\title{
Topology Optimized Photonic Wire Splitters
}

Frandsen, Lars Hagedorn; Borel, Peter Ingo; Jensen, Jakob Søndergaard; Sigmund, Ole

Published in:

CLEO/QELS 2006 Technical Digest CD-Rom

Link to article, DOI:

10.1109/CLEO.2006.4627889

Publication date:

2006

Document Version

Publisher's PDF, also known as Version of record

Link back to DTU Orbit

Citation (APA):

Frandsen, L. H., Borel, P. I., Jensen, J. S., \& Sigmund, O. (2006). Topology Optimized Photonic Wire Splitters. In CLEO/QELS 2006 Technical Digest CD-Rom (pp. 1-2). IEEE. https://doi.org/10.1109/CLEO.2006.4627889

\section{General rights}

Copyright and moral rights for the publications made accessible in the public portal are retained by the authors and/or other copyright owners and it is a condition of accessing publications that users recognise and abide by the legal requirements associated with these rights.

- Users may download and print one copy of any publication from the public portal for the purpose of private study or research.

- You may not further distribute the material or use it for any profit-making activity or commercial gain

- You may freely distribute the URL identifying the publication in the public portal

If you believe that this document breaches copyright please contact us providing details, and we will remove access to the work immediately and investigate your claim 


\title{
Topology Optimized Photonic Wire Splitters
}

\author{
L.H. Frandsen and P.I. Borel \\ $C O M \bullet D T U$, Department of Communications, Optics and Materials, Nano $\bullet D T U$, \\ Technical University of Denmark, DK-2800 Kgs Lyngby, Denmark \\ lhf@com.dtu.dk,pib@com.dtu.dk \\ http://pipe.com.dtu.dk \\ J.S. Jensen and O. Sigmund \\ Department of Mechanical Engineering, Technical University of Denmark, DK-2800 Kgs. Lyngby, Denmark \\ jsj@mek.dtu.dk, sigmund@mek.dtu.dk \\ http://www.topopt.dtu.dk
}

\begin{abstract}
Photonic wire splitters have been designed using topology optimization. The splitters have been fabricated in silicon-on-insulator material and display broadband low-loss $3 \mathrm{~dB}$ splitting in a bandwidth larger than $100 \mathrm{~nm}$.

(C)2006 Optical Society of America

OCIS codes: (000.3860) Mathematical methods in physics; (000.4430) Numerical approximation and analysis; (130.2790) Guided waves; (130.3130) Integrated optics materials; (220.4830) Optical systems design; (230.5440) Polarization-sensitive devices; (230.7390) Waveguides, planar; (999.9999) Photonic crystals.
\end{abstract}

\section{Introduction}

Integrated optical circuits comprising several on-chip functionalities and high component densities demand low-loss routing of optical signals over small areas [1]. In the silicon platform, photonic wires offer the possibility to guide light efficiently with very small losses [2] due to the high index contrast between silicon and the cladding material, which is typically air or silica. Thus, waveguide bends, ring resonators, and splitters can be designed with very compact sizes by using simple design strategies [3]. However, to optimize the performance of ultra compact components new inverse design tools need to be utilized.

Topology optimization [4] has previously been utilized to optimize the performance of different photonic crystal waveguide components $[5,6]$. Here, we apply this inverse design method to design a compact, broadband and low-loss photonic wire splitter.
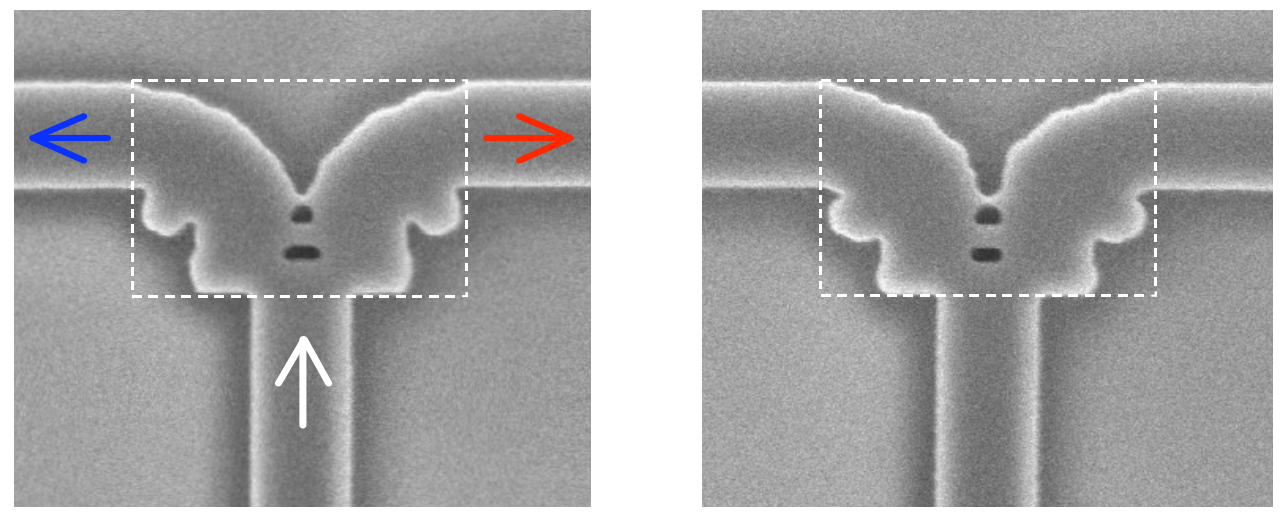

Figure 1. Scanning electron micrographs of the optimized and fabricated photonic wire splitters. The dashed boxes sketch the design areas chosen in the topology optimization.

\section{Design and fabrication}

The generic photonic wire (PhW) splitter is constructed by combining three PhWs of width $440 \mathrm{~nm}$ to form a Tjunction. The topology optimization method is applied to a $\sim \mu \mathrm{m}^{2}$ design area of the T-junction (dashed box in Fig. 1). The silicon material will be redistributed within the design area without any restrictions to the shape and form of the final T-junction. The goal criteria are to optimize the transmission in each of the two output arms and to obtain a low-loss and broadband 3-dB splitting. To test the robustness of the method two different designs have been obtained by choosing different target frequencies in the optimizations. Both designs have been fabricated in a 


\section{CMV4.pdf}

silicon-on-insulator material by utilizing e-beam lithography and an $\mathrm{SF}_{6}$-based inductively coupled plasma etch. The thickness of the top silicon layer is $\sim 320 \mathrm{~nm}$ and the buried box oxide is $1 \mu \mathrm{m}$. Figure 1 show scanning electron micrograph images of the two fabricated $\mathrm{PhW}$ splitters. It is seen that the optimized splitters look similar with structured parts on the inner side of the bends and small holes in the middle of the junction.

\section{Results and conclusion}

The PhW splitters have been characterized optically for the transverse electric mode by using a laser source in the wavelength region from $1480-1580 \mathrm{~nm}$. Figure 2 shows the obtained transmission spectra for the splitters shown in Fig. 1, left and right, respectively. The transmission spectra have been normalized to a straight photonic wire of similar width to extract the splitting loss.
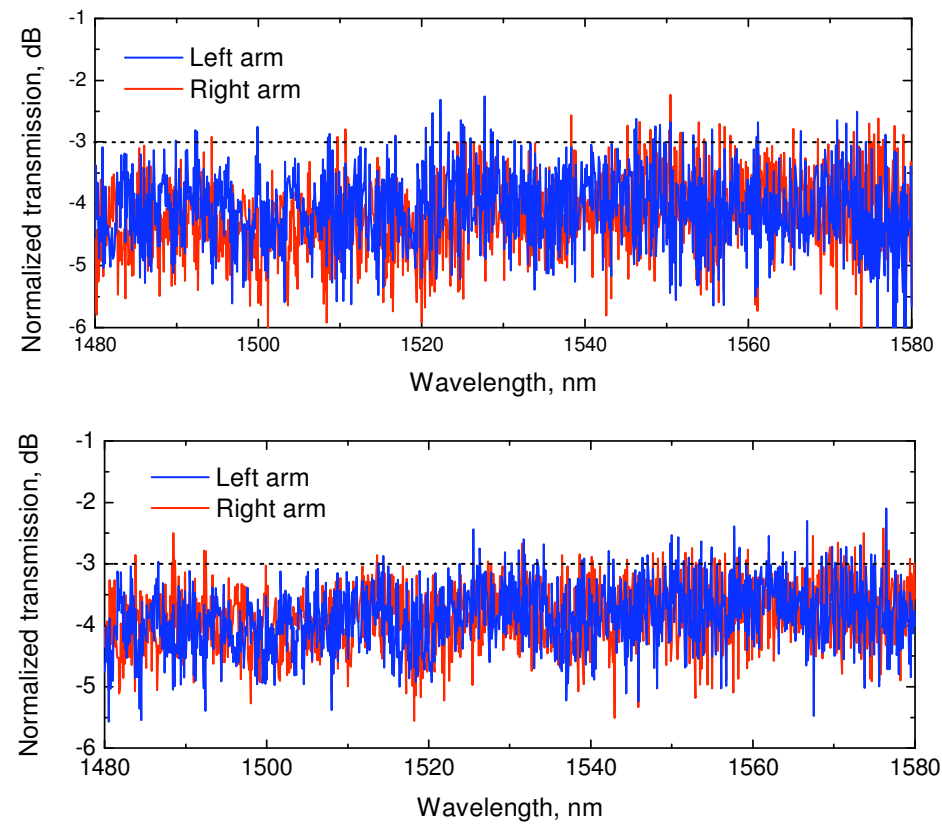

Figure 2. Normalized transmission spectra for the photonic wire splitters shown in Fig. 1, (top) left and (bottom) right splitter.

From the figure it is seen that both optimized splitters split light equivalently to each arms in the investigated wavelength range. The average values of the normalized transmissions are $-4.1 \pm 0.6 \mathrm{~dB}$ and $-3.9 \pm 0.6 \mathrm{~dB}$ over the $100 \mathrm{~nm}$ wavelength region for the left and right splitter in Fig. 1, respectively. The excess loss around $1 \mathrm{~dB}$ for each splitter is mainly due to roughness in the T-junction. In this way, we have shown that topology optimization can be used to design ultra compact photonic wire splitters with a footprint as small as $1 \mu \mathrm{m}^{2}$, which perform with low losses over a broad wavelength range. We believe that topology optimization is a strong inverse design tool for realizing compact and optimized photonic crystal and photonic wire components.

\section{References}

[1] Fukazawa, T., Sakai, A., and Baba, T., "H-tree-type optical clock signal distribution circuit using a Si photonic wire waveguide", Jpn. J. Appl. Phys., 41, 1461-1463 (2002).

[2] Vlasov, Y.A. \& McNab, S.J, "Losses in single-mode silicon-on-insulator strip waveguides and bends", Opt. Express, 12, 1622-1631 (2004).

[3] Sakai, A., Fukazawa, and Baba, T., "Low loss ultra-small branches in a silicon photonic wire waveguide", IEICE Trans. Electron., E85-C, 1033-1038 (2002).

[4] M. P. Bendsøe and O. Sigmund, Topology Optimization - Theory, Methods and Applications. Springer Verlag, Berlin Heidelberg (2003). [5] P.I. Borel, L.H. Frandsen, A. Harpøth, M. Kristensen, J.S. Jensen and O. Sigmund, "Topology Optimised Broadband Photonic Crystal YSplitter", Electronics Letters, Vol. 41, 2, 69-71 (2005).

[6] J. S. Jensen and O. Sigmund, "Systematic design of photonic crystal structures using topology optimization: Low-loss waveguide bends", Appl. Phys., Vol. 84, 12, 2022-2024 (2004).

\section{Acknowledgments}

This work was supported in part by the Danish Technical Research Council through the research programs 'Planar Integrated PBG Elements' (PIPE) and 'Designing bandgap materials and structures with optimized dynamic properties'. 